\title{
Ethical Issues in Mandatory Vaccination
}

\author{
Manmeet Kaur Gill ${ }^{1}$, Sahiba Kukreja ${ }^{2}$, Rahul Mannan ${ }^{3}$, Anureet Gill ${ }^{4}$, AP Singh ${ }^{5}$
}

${ }^{1}$ Associate Professor, Department of Microbiology, Sri Guru Ram Institute of Medical Sciences and Research, Sri Amritsar.

${ }^{2}$ Professor \& Head, Department of Biochemistry, Sri Guru Ram Institute of Medical Sciences and Research, Sri Amritsar.

${ }^{3}$ Professor, Department of Pathology, Sri Guru Ram Institute of Medical Sciences and Re-search, Sri Amritsar.

${ }^{4}$ Undergraduate BDS 3rd year student, Sri Guru Ram Institute of Dental Sciences and Research, Sri Amritsar.

${ }^{5}$ Professor, Department of Anaesthesia, Sri Guru Ram Institute of Medical Sciences and Re-search, Sri Amritsar.

Corresponding Author : Manmeet Kaur Gill

E-mail:drmanmeetgill@gmail.com

\begin{abstract}
Vaccination carries significant health benefits and is a widely accepted intervention for public health care. Compulsory vaccination was first introduced in Europe and United States of America for smallpox and mandatory vaccination is still in practice in few counties across the globe. Although vaccine mandates are an important tool for achieving high vaccination coverage but enforcement of such mandates by governments often precipitates debates on ethical issues. There are people who believe that authorities emphasize more on the benefits of vaccination and trivializes the adverse effects. They do not accept existing medical or safety evidences. On the other hand, some communities disagree because they have their religious or philosophical beliefs which do not support vaccination. They think these regulations infringe upon an individual's autonomy. There is an inextricable link between public health care and human rights which cannot be ignored. This paper aims to identify various ethical issues concerning mandatory vaccination.
\end{abstract}

Key words: ethical issues, immunization, vaccine mandates.

Vaccination is a proven and widely accepted intervention for public health care. It has an important role in curtailing the morbidity and mortality due to diseases which are preventable $[1,2]$. Since the advent of vaccines, wide use of immunization has significantly reduced the incidence of serious infections like polio, measles and lead to complete eradication of smallpox, worldwide. Vaccination, not only provide immunity to the person immunized but also protect the community. If majority of the population (90\%) is vaccinated against a disease, it will protect even those who are not vaccinated (eg. newborns). This is called as "Herd Immunity". There are 26 diseases for which vaccines are available and many more for which vaccines are in developmental phase, "pipeline vaccines" [3]. Immunization schedule varies from country to country but most of the countries include diphtheria, pertussis, tetanus, poliomyelitis, tuberculosis, measles and Hepatitis B in their schedule.

\section{A brief history of vaccination}

History of vaccination dates back to ancient times when primal attempts were made to prevent disease in humans. There are evidences that indicates that for Smallpox which was prevalent in all 
regions of the world, inoculations were practiced in China, India and Turkey around 1000 AD [48]. This was called as Variolation, a method first used to immunize an individual against smallpox (Variola) with material taken from a patient or a recently variolated individual in the hope that a mild, but protective infection would result. Small pox vaccine was discovered much later in 1798 by Edward Jenner. He observed that a person inoculated with cow pox virus would develop a mild cow pox infection but was protected against smallpox infection. Soon after he published his work, smallpox vaccination spread to many parts of the world [9-10].

\section{Indian scenario}

Smallpox vaccine arrived in India in 1802 but acceptance by general public was low due to certain beliefs and misconceptions. Variolation continued despite ban [11]. In 1880, The Compulsory Vaccination Act was passed to prohibit inoculation and to make the vaccination of children compulsory in certain states but ironically it largely remained confined to papers only.

Other important events during this period were Cholera vaccine trial in 1893 and development of plague vaccine in 1897 by Dr Haffkine, in India. The lab where he developed the plague vaccine was named after him 'Haffkine Institute' in 1925 [12].

At the time of independence although vaccines for four diseases viz smallpox, cholera, plague and typhoid, were available in the country, still India accounted for maximum number of smallpox cases in the world, cholera and plague epidemics were occurring and tuberculosis was gaining an epidemic proportion. However in 1948, first BCG vaccination programme was conducted and also a BCG vaccine laboratory was set up in Guindy same year [13-14]. In 1962 National Tuberculosis Control Programme (NTCP) came into being focusing on early diagnosis and treatment of the disease and BCG vaccination was part of this programme [15].

In 1967-68, smallpox eradication policy was reformulated with more focus on surveillance and containment of the outbreaks. Vaccination technique (1969) and vaccine (1971) were improved. All these intensified efforts by the government paid off and India was declared smallpox free in 1977 and world in 1980. In 1988 a resolution for polio eradication by 2000, was passed by World Health Assembly and Government of India also joined this programme. Beginning with Tamil $\mathrm{Nadu}$, state wise polio vaccination campaign 'Pulse Polio', was established by the government of India to eliminate poliomyelitis by vaccinating all children under the age of five years against the polio virus. In 1997 an organized surveillance was established as National Polio Surveillance Project (NPSP). The last case of wild polio virus (type1) was reported on January 13, 2011 in West Bengal and on 25th February, 2012, WHO removed India from list of polio endemic countries. The South-East Asia Regional Certification Commission for Polio Eradication declared the SouthEast Asia Region of the WHO, polio-free on 27th March 2014 [16-19].

\section{National Immunization Schedule (NIS) in India}

National immunization Programme was introduced in 1978 as Expanded Programme of Immunization (EPI) and in 1985 and it was expanded as Universal Immunization Programme (UIP) to be implemented in phased manner to cover all districts in the country by 1989-90. In 1992, UIP become a part of Child Survival and Safe Motherhood Programme. Since 2005, immunization activities have been an important component of National Reproductive and Child Health Programme and are currently one of the key areas under National Rural Health Mission (NRHM). The UIP in India is one of the largest in the world, targeting 27 million infants and 30 million pregnant women every year. Under this programme, Government of India is currently providing free vaccines, against eleven life threatening diseases ie. Tuberculosis, Diphtheria, Pertussis, Tetanus, Polio, Hepatitis B, Rubella, Meningitis and pneumonia due to Haemophilus influenzae type b (Hib), Measles, Japanese Encephalitis (JE) and Rotavirus diarrhoea [1]. However, the average coverage of the UIP vaccines at the national level is below 50\% [20].

On 25th December 2014 Mission Indradhanush was launched under National Health Mission. It aims to immunize all children under 2 years of age, as well as all pregnant women, against seven vaccine preventable diseases i.e. Diphtheria, Pertussis, Tetanus, Poliomyelitis, Tuberculosis, Measles and Hepatitis B (Table 1). In 2016, four new vaccines were added namely Rubella, Rotavirus, Injectable Polio Vaccine Bivalent and Japanese Encephalitis [20]. 
Table 1: National Immunization Schedule (NIS) for Infants, Children and Pregnant Women

\begin{tabular}{|c|c|c|c|c|}
\hline \multicolumn{5}{|c|}{ National Immunization Schedule } \\
\hline Vaccine & When to give & Dose & Route & Site \\
\hline \multicolumn{5}{|c|}{ For Infants } \\
\hline BCG & $\begin{array}{l}\text { At birth or as early as } \\
\text { possible till one year of age }\end{array}$ & $\begin{array}{l}0.1 \mathrm{ml}(0.05 \mathrm{ml} \\
\text { until } 1 \text { month of } \\
\text { age })\end{array}$ & Intra -dermal & $\begin{array}{l}\text { Left Upper } \\
\text { Arm }\end{array}$ \\
\hline Hepatitis B Birth dose & $\begin{array}{l}\text { At birth or as early as } \\
\text { possible within } 24 \text { hours }\end{array}$ & $0.5 \mathrm{ml}$ & Intramuscular & $\begin{array}{l}\text { Antero-lateral } \\
\text { side of mid- } \\
\text { thigh LEFT }\end{array}$ \\
\hline OPV Birth dose & $\begin{array}{l}\text { At birth or as early as } \\
\text { possible within the first } 15 \\
\text { days }\end{array}$ & 2 drops & Oral & - \\
\hline OPV $1,2 \& 3$ & $\begin{array}{l}\text { At } 6 \text { weeks, } 10 \text { weeks \& } 14 \\
\text { weeks }\end{array}$ & 2 drops & Oral & - \\
\hline $\begin{array}{l}\text { IPV (inactivated Polio } \\
\text { Vaccine) }\end{array}$ & 14 weeks & $0.5 \mathrm{ml}$ & Intramuscular & $\begin{array}{l}\text { Anterolateral } \\
\text { side of mid- } \\
\text { thigh-RIGHT }\end{array}$ \\
\hline Pentavelant $1,2 \& 3$ & $\begin{array}{l}\text { At } 6 \text { weeks, } 10 \text { weeks \& } 14 \\
\text { weeks }\end{array}$ & $0.5 \mathrm{ml}$ & Intramuscular & $\begin{array}{l}\text { Anterolateral } \\
\text { side of mid- } \\
\text { thigh-LEFT }\end{array}$ \\
\hline Rota Virus Vaccine & $\begin{array}{l}\text { At } 6 \text { weeks, } 10 \text { weeks \& } 14 \\
\text { weeks }\end{array}$ & 5 drops & Oral & - \\
\hline Measles $1^{\text {st }}$ Dose & $\begin{array}{l}9 \text { completed months- } 12 \\
\text { months. (give up to } 5 \text { years } \\
\text { if not received at } 9-12 \\
\text { months age) }\end{array}$ & $0.5 \mathrm{ml}$ & Subcutaneous & $\begin{array}{l}\text { Right Upper } \\
\text { Arm }\end{array}$ \\
\hline Vitamin A, $1^{\text {st }}$ Dose & At 9 months with measles & $1 \mathrm{ml}(1$ lakh IU) & Oral & - \\
\hline \multicolumn{5}{|l|}{ For children } \\
\hline DPT $1^{\text {st }}$ booster & 16-24 months & $0.5 \mathrm{ml}$ & Intramuscular & $\begin{array}{l}\text { Anterolateral } \\
\text { side of mid- } \\
\text { thigh-LEFT }\end{array}$ \\
\hline OPV Booster & 16-24 months & 2 drops & Oral & \\
\hline Measles $2^{\text {nd }}$ dose & 16-24 Months & $0.5 \mathrm{ml}$ & Subcutaneous & $\begin{array}{l}\text { Right Upper } \\
\text { Arm }\end{array}$ \\
\hline $\begin{array}{l}\text { Vitamin } A\left(2^{\text {nd }} \text { to } 9^{\text {th }}\right. \\
\text { dose })\end{array}$ & $\begin{array}{l}16 \text { months with DPT/OPV } \\
\text { booster, then, one dose } \\
\text { every } 6 \text { month up to the age } \\
\text { of } 5 \text { years) }\end{array}$ & $2 \mathrm{ml}$ (2 lakh IU) & Oral & - \\
\hline
\end{tabular}




\begin{tabular}{|c|l|c|l|l|}
\hline DPT $2^{\text {nd }}$ Booster & $5-6$ years & $0.5 \mathrm{ml}$. & Intramuscular & $\begin{array}{l}\text { Left Upper } \\
\text { Arm }\end{array}$ \\
\hline TT & 10 years \& 16 years & $0.5 \mathrm{ml}$ & Intramuscular & Upper Arm \\
\hline
\end{tabular}

\section{Risks and benefits of vaccination}

There are always some risks associated with immunization programmes and there has always been an anti-vaccination lobby, vociferous in its objections against mandatory vaccinations. Vaccine side effects may range from mild to sometimes life-threatening conditions. In 1948, in Kyoto, Japan, 68 of 606 children died after diphtheria immunization as a result of improper manufacture of toxoids which reverted to toxin, with disastrous effects [21]. In 1976, in the USA, the vaccination programme against swine flu was stopped because it was thought to be associated with a concomitant increase in Guillain-Barré syndrome [22]. In 1976, in Britain, "National Childhood Encephalopathy Study" (NCES), first largest prospective case-control study of vaccine-induced encephalopathy, thought to be related to whole cell pertussis vaccine and caused a serious public alarm, was conducted [23]. Bacille Calmette-Gue $\square$ rin (BCG) is a widely used and a safe relatively vaccine, even though its efficacy ranges from zero to $80 \%$. But it can cause disseminated infection, especially in immunocompromised hosts [24].

Measles-Mumps-Mubella (MMR) vaccine was believed to be associated with autism. The adverse effects are attributed to a compound thimerosol, in the vaccines. Although there are no data to support any association between MMR vaccine and autism but bad publicity resultant in decrease in MMR vaccination, and consequently resulted in increased measles incidence in certain communities [25]. The list is endless and beyond the scope of this article.

\section{Ethical issues related to vaccination}

Although vaccines are responsible for accomplishments of many global public health aims, such as the eradication of smallpox and significant reductions in other serious infections, still vaccinations have been the subject of various ethical controversies. The key ethical issues related to vaccine regulation, development, and use usually involve (1) vaccine mandates (2) research and testing (3) informed consent (4) access disparities.

\section{Vaccine mandates}

Enforcing mandatory vaccinations is one of the strategies that some countries adopted for high vaccination coverage among children. Compulsory vaccination was first introduced in Europe and United States of America (USA) for smallpox, around 1850. Indian Government passed the compulsory vaccination act in 1892 to prohibit inoculation and to make the vaccination of children compulsory, against smallpox [4].

Mandatory vaccination is still in practice in few counties across the globe. In USA, all 50 states mandate certain immunization before school entry. However certain exemptions are permitted on medical grounds in all the states, 48 states allow religious exemptions and 20 states allow exemptions for philosophical reasons [26]. In Australia childhood vaccination, before school entry, was legislated in 1999 [27]. In 2010, a survey on mandatory vaccination in Europe was conducted and information was collected from all 27 EU Member States, Iceland and Norway. Out of total, 15 countries did not have any mandatory vaccinations; the remaining 14 had at least one mandatory vaccination included in their programme [28]. But there are counties like Italy, who have moved from compulsory to voluntary immunisation programme in certain regions that have reached the herd immunity, while providing effective monitoring of the incidence of communicable disease [29].

\section{Ethical issues with vaccine mandates}

Although mandatory vaccination is an important tool in improving compliance to vaccination programmes; but enforcement of such mandates by governments often precipitates debates on ethical issues. Two such major issues are - 


\section{Risks of vaccination}

There are people who believe that authorities emphasize more on the benefits of vaccination and trivialize the adverse effects. They do not accept existing medical or safety evidences. Similar views were highlighted in a paper by Angus Dawson in which he critically reviewed the common objections to the preventive medicine, referred as "prevention problem". He argues that the successes of immunization programmes generally lie in their ability to create herd immunity. The key elements of the problems with these programs are "a) preventive public health measures are performed on asymptomatic individuals; (b) every such public health intervention will carry a risk of harm; (c) the benefits of such interventions lie at the level of populations, whilst the risks of harm are borne by the individual participants in the programme. Conclusion: such preventive programmes are unethical (given distribution of risks and benefits." [30].

\section{Religious or philosophical beliefs}

Some communities disagree because they have their religious or philosophical beliefs which do not support vaccination. They think these regulations infringe upon an individual's autonomy and beliefs [31]. One such example is the issues related to Human papilloma virus (HPV) vaccine, which was approved by FDA in 2006 to be used for immunization of girls aged 11-12 years. When various state legislations in USA attempted to mandate the vaccination, ethical objections, which arose against the mandate, ranged from religious concerns that a vaccine to protect against an STD contradicts abstinence-based messages; and human rights questions about the fairness of providing a vaccine to one sex only $[32,33]$.

Basically, any kind of mandatory testing, treatment or isolation is violation of rights of people. In public health practice. Out of four principles of Bioethics, principal of beneficence often carry more weightage than the principle of autonomy and that is why most of the vaccination programmes have coercive and paternalistic approach.

John Stuart Mill stated that "power can be rightfully exercised against somebody against her/his will if it is done to prevent harm to others" [34]. In the context to immunization, such coercion is often justified on the grounds of eradicating a life-threatening disease [35].

\section{Informed consent}

Informed consent is a process for getting permission before conducting a healthcare intervention on a person, or for disclosing personal information. It not only helps to develop trust and confidence in the patient, for the doctor but also helps the doctor to carry out the planned medical intervention in a more composed manner, being confident in the protection of this doctrine if anything untoward occurs [36]. However, even though serious life-threatening complications due to vaccinations have been reported, but informed consent for vaccination not much in practice. Also, informed consent in relation to immunizations has a limited direct application in pediatrics as here generally the parents provide the consent.

\section{Global scenario}

In USA, there is no Federal law which makes informed consent mandatory before vaccination but the National Childhood Vaccine Injury Act of 1986 requires that doctors should give vaccine recipients, or their parents, a Vaccine Information Statement (VIS). It provides the basic information about the risks and the benefits of the vaccine and thus provides the information, a patient or parent needs to make an informed decision [37].

\section{Indian scenario}

In India, valid consent has been taken for vaccine trials; but whether they were informed or not is still a question. In 2009, the Ministry of Health and Family Welfare (MOHFW), Indian Council of Medical Research (ICMR), PATH and the state governments of Andhra Pradesh and Gujarat conducted a 'démonstration project' to determine the feasibility of the introduction of the vaccine, against, Human Papillomavirus (HPV) in India. In these trials, three doses of the HPV vaccine were administered to 16,000 girls, in the age group of 10-14 years, without monitoring the adverse reactions, which lead to the death of four girls in Andhra Pradesh and two girls in Gujarat. On the 
top of it, the vaccine was administered in camps organized in school campuses and wardens of the schools were allowed to provide consent for hundreds of children, without consulting their parents. This project was widely criticized for violating all scientific and ethical norms [38-39].

\section{What is need for informed consent}

In USA in 1983, children were required to have 10 total injections of the polio, MMR, and DTP vaccines prior to entering the public schools. The policy created debilitating injury in some of the children and parents of these children sued the pharmaceutical companies and got huge claims. Vaccine manufacturers companies then approached U.S government and threatened to stop production of vaccines in light of the settlements. This gave way to the legislation of 1986, The National Childhood Vaccine Injury Act. Under this Act, the pharmaceutical companies gained their freedom from liability if their product causes harm; because U.S government outlined vaccines as "unavoidably unsafe" [40]. After this, began the tax collection from the sale of every vaccine to be placed in a compensation fund for the injured, thereby the product consumers are now liable for product failures.

\section{Equity in distribution of vaccines}

Health disparities exist both on a global level and within our nation's health care system, where we see persistent racial, ethnic and socioeconomic disparities in medical care and overall health. In India, Equity in health care, have always been a guiding principle with a commitment to serve the poor and underprivileged, in formulating a health policy document. First official National Health Policy was put forward in 1983, reprise the need for universal comprehensive care [41]. However, the utilization of preventive health services like immunizations remains suboptimal. The UIP in India is one of the largest in the world, but the average coverage of the UIP vaccines at the national level is below $50 \%$. In a survey (2011), it was found that nearly 22.4 million children globally, were partially vaccinated till the age of 12 and remained at risk for vaccine-preventable communicable diseases. More than half of these partially vaccinated children were reported to be residing in India (32\%), Nigeria (14\%) and Indonesia (7\%). There are disparities in the utilization of these services by gender, socioeconomic status, and geography. In 2005-2006, the national immunization coverage was $44 \%$ and major inequalities in immunization exist by socioeconomical status and education. Inequalities also exist by caste: in 2005-2006, immunization coverage among scheduled tribes and scheduled castes was $31.3 \%$ and $39.7 \%$ respectively, compared to $53.8 \%$ among other castes. Coverage remains higher in urban areas (58\%) as compared to rural areas (39\%). Gender gap has also increased with an absolute of $2.6 \%$ in 1993 and increasing to $3.8 \%$ in 2006. Realizing the roadblocks in immunisation programmes, the current government has launched Mission Indradhanush in December 2014 as a special drive to vaccinate all unvaccinated and partially vaccinated children by 2020 under the UIP [42].

\section{Ethical considerations}

These disparities in India and globally, signal the need for continued efforts by Public health and medical officials, to ensure equal opportunities for people to benefit from vaccination. In concordance with the forth principal of bioethics, distributive justice requires fair allocation of resources. Children should be guaranteed 'the right to basic health care services'. Realizing the gravity of the situation, the current Indian government has launched Mission 'Indradhanush' in December 2014 as a special drive to vaccinate all unvaccinated and partially vaccinated children by 2020 under the UIP.

\section{Conclusions}

In conclusion, mandatory vaccination may not lead to utopian state of $100 \%$ vaccination uptake rather it is fraught with maladies and societal/religious backlash. Coercion and forced vaccination can lead to a state where babble of misinformation can lead to cacophony of chaotic thought processes and fractured ground realities. Instead integrating vaccination as a part of healthy positive vital life is the answer to the current pressing need of improved vaccine uptake. A healthy discussion on mandatory vaccination and its benefits on future generation can have a positive 
momentum and can dampen the current environment of anti-vaccine narratives swirling around. Along with this, resource back up (such as adequacy of vaccine supply and vaccine related health services) and respecting the cultural diversity and specific community needs will lead to more and more vaccine acceptance redundant the ever-occurring debate and need of vaccine mandates.

Hence research findings, sharing experiences, availability of trained medical health with aforementioned repeating the local culture, sensitivity towards customs/beliefs/ societal norms and integrating the vaccine acceptability within the cultural and religious milieu of a specific population may be the answer in increasing the vaccine acceptability rates in the resource challenged third world countries of Asia and Africa such as ours. This in turn will lead to control of vaccine preventable diseases, leading to alleviating a significant population form morbidity and mortality associated with them in absence of such prophylactic measures. Vaccine mandate or policy of local targeted inclusivity- the jury is still out there.

\section{REFERENCES}

1. Arora S. National Immunization Schedule India: A Review. Res Rev J Immunol 2017;7(3):6-10.

2. Madhavi Y. Vaccine policy in India. PLoS Med 2005;2(5):e127.

3. World Health Organization. Global immunization data. May 16, 2018. Available from http://www.who.int/immunization/diseases/en/

4. Lahariya C. A brief history of vaccines \& vaccination in India. Ind J Med Res 2014;139(4):491-511.

5. Fenner F, Henderson DA, Arita I, Jezek Z, Ladnyi ID. Smallpox vaccine and vaccination in the intensified smallpox eradication programme. Smallpox and its Eradication 1988:539-92.

6. Dowdle WR. The principles of disease elimination and eradication. Bulletin of the World Health Organization. 1998;76(Supp1 2):22.

7. Fitchett JR, Heymann DL. Smallpox vaccination and opposition by anti-vaccination societies in 19 th century Britain. Hist Med 1995;2:e17.

8. Riedel S. Edward Jenner and the history of smallpox and vaccination. Baylor University Medical Center Proceedings 2005;18(1):21-5.

9. Holwell JZ. An Account of the Manner of Inoculating for the Small Pox in the East Indies: With Some Observations on the Practice and Mode of Treating that Disease in Those Parts.... By JZ Holwell, FRS. London:: printed for T. Becket, and PA De Hondt; 1767.

10. Wujastyk D. A pious fraud: the Indian claims for pre-Jennerian smallpox vaccination. In Meulenbeld G, Wujastyk D. Studies on Indian Medical History. Delhi: Motilal Banarsidass Publishers; 2001;pp121-54.

11. Bhattacharya S, Jackson M. London: Wellcome Institute. Vaccination against smallpox in India. 2005.

12. Wikipedia Haffkine Institute. May 16, 2018. Available from: https://en.wikipedia.org/wiki/Haffkine_Institute.

13. Madras: Tamil Nadu State Archive, Health Department. 1950; 809.

14. Central TB Division. Tuberculosis Control India. Directorate General of Health Services. May 16,2018]. Available from: http://www.tbcindia.nic.in/history.html .

15. Khatri GR. National tuberculosis control programme. J Indian Med Assoc 1996;94:372- 84.

16. Lahariya C. Global eradication of polio: the case for" finishing the job". Bull WHO 2007;85:48792.

17. New Delhi: MoHFW. Ministry of Health and Family Welfare. Polio eradication in India. 2021.

18. The National Polio Surveillance Project. A Government of India-WHO Colloboration. May 16, 2018. Available from: www.npspindia.org.

19. World Health Organization. India records one 55. year without polio cases. May 16, 2018. http://www.who.int/mediacentre/news/releases/2012/polio_20120113/en/index .html.

20. Universal Immunization Programme. May 16, 2018. Available from: https://mohfw.gov.in/sites/default/files/5628564789562315.pdf.

21. Stratton KR, Howe CJ, Johnston RB. Research strategies for assessing adverse events associated with vaccines: a workshop summary. National Academies; 1994.

22. Stowe J, Andrews N, Wise L, Miller E. Investigation of the temporal association of Guillain-Barre syndrome with influenza vaccine and influenza like illness using the United Kingdom General Practice Research Database. Am J Epidemiol 2008;169(3):382-8. 
23. Shorvon S, Berg A. Pertussis vaccination and epilepsy - an erratic history, new research and the mismatch between science and social policy. Epilepsia 2008;49(2):219-25.

24. Snider Jr DE. Ethical issues in tuberculosis vaccine trials. Clin Infect Dis 2000;30(Suppl 3):S271-5.

25. Isaacs D, Kilham HA, Alexander S, Wood N, Buckmaster A, Royle J. Ethical issues in preventing mother-to-child transmission of hepatitis B by immunisation. Vaccine 2011;29(37):6159-62.

26. Malone KM, Hinman AR. Vaccination mandates: the public health imperative and individual rights. Law Pub Health Pract 2003;3:262-84..

27. Australian Department of Health and Ageing. The Seven Point Plan. May 18, 2018. Available from www.health.gov.au.

28. Giammanco GM, Bechini A, Urone N, Bonura F, Muli SL, De Grazia S, Bellini I, Tiscione E, Boccalini S, Nastasi A. Is Italian population protected from Poliovirus? Results of a seroprevalence survey in Florence, Italy. Hum Vacc Immunotherapeut 2018 May 10(just-accepted Epub ahead of print).

29. Moran NE, Gainotti S, Petrini C. From compulsory to voluntary immunisation: Italy's National Vaccination Plan (2005-7) and the ethical and organisational challenges facing public health policymakers across Europe. J Med Ethics 2008;34(9):669-74.

30. Dawson A. Vaccination and the prevention problem. Bioethics 2004;18(6):515-30.

31. Salmon DA, Teret SP, MacIntyre CR, Salisbury D, Burgess MA, Halsey NA. Compulsory vaccination and conscientious or philosophical exemptions: past, present, and future. Lancet 2006;367(9508):436-42.

32. Javitt G, Berkowitz D, Gostin LO. Assessing mandatory HPV vaccination: who should call the shots?. J Law Med Ethics 2008;36(2):384-95.

33. Colgrove J. The ethics and politics of compulsory HPV vaccination. New Eng J Med 2006;355(23):2389-91.

34. Vermeersch E. Individual rights versus societal duties. Vaccine 1999;17:S14-7.

35. Johari V. Identifying ethical issues in the development of vaccines and in vaccination. Indian J Med Ethics 2017;2(2):88-93.

36. Rajput M, Sharma L. Informed consent in vaccination in India: medicolegal aspects. Human Vaccines 2011;7(7):723-7.

37. Centers for Disease Control and Prevention. Fact sheet for vaccine information statements. May 20, 2018. Available from http://www.cdc.gov/vaccines/hcp/vis/about/facts-vis.html

38. Sarojini NB, Srinivasan S, Madhavi Y, Srinivasan S, Shenoi A. The HPV vaccine: science, ethics and regulation. Econ Pol Wkly 2010;45(27):27-34.

39. Ramanathan M, Varghese J. The HPV vaccine demonstration projects: we should wait, watch and learn. Indian J Med Ethics 2010;7:43-5.

40. HRSA. Part 2 - National vaccine injury compensation program. 42 USC chapter $6 \mathrm{a}$, public health service title 42 the public health service subchapter XIX vaccines. 1986. 42 U.S.C. 300aa-22(b)(1); 47.

41. Delhi N. Ministry of Health and Family Welfare, Government of India; 1987. Pharmacopoeial Standards for Ayurvedic Formulations, Central Council for Research for Ayurveda and Siddha, Revised Ed. 1983:1-20.

42. Balarajan Y, Selvaraj S, Subramanian SV. Health care and equity in India. Lancet 2011;377(9764):505-15.

Acknowledgements - Nil

Source of Funding - Nil

Conflict of Interest - Nil 